\title{
Adenoma miss rate of polypectomy-referring hospitals is high in Korea
}

\author{
Ju Hyun Seo ${ }^{1}$, Bo-In Lee ${ }^{1}$, Kyungjin Lee ${ }^{1}$, Jae Myung Park ${ }^{1}$, Jin Soo Kim¹, Young-Seok Cho ${ }^{1}$, \\ Kang-Moon Lee ${ }^{2}$, Sang Woo Kim³ ${ }^{3}$ Hwang $\mathrm{Choi}^{4}$, and Myung-Gyu Choi ${ }^{1}$
}

\begin{abstract}
${ }^{1}$ Division of Gastroenterology, Department of Internal Medicine, Seoul St. Mary's Hospital, College of Medicine, The Catholic University of Korea, Seoul; ${ }^{2}$ Division of Gastroenterology, Department of Internal Medicine, St. Vincent Hospital, College of Medicine, The Catholic University of Korea, Suwon; ${ }^{3}$ Division of Gastroenterology, Department of Internal Medicine, Uijeongbu St. Mary's Hospital, College of Medicine, The Catholic University of Korea, Uijeongbu; ${ }^{4}$ Division of Gastroenterology, Department of Internal Medicine, Incheon St. Mary's Hospital, College of Medicine, The Catholic University of Korea, Incheon, Korea
\end{abstract}

Received: March 11, 2018 Revised : April 30, 2018 Accepted: October 21, 2018

\section{Correspondence to \\ Bo-In Lee, M.D}

Division of Gastroenterology, Department of Internal Medicine, Seoul St. Mary's Hospital, College of Medicine, The Catholic University of Korea, 222 Banpo-daero, Seocho-gu, Seoul 06591, Korea

Tel: +82-2-2258-2044

Fax: +82-2-2258-2083

E-mail:gidoc4u@catholic.ac.kr
Background/Aims: We evaluated the miss rates of polyps, adenomas, and advanced neoplasia of polypectomy-referring hospitals and risk factors for missed adenomas.

Methods: We compared medical records and electronic images of initial colonoscopies from polypectomy-referring hospitals with those of corresponding therapeutic colonoscopies from Seoul St. Mary's Hospital obtained from May 2014 to February 2016.

Results: A total of 147 patients $(56.6 \pm 12.1$ years, 37 females) were included. The mean number of polyps and adenomas detected on initial colonoscopy was $2.4 \pm$ 1.7 and $1.7 \pm 1.4$, respectively. The mean number of additionally detected polyps and adenomas per patient during therapeutic colonoscopy was $1.4 \pm 1.8$ and $1.0 \pm$ 1.5, respectively. Pooled miss rate for polyps, adenomas, and advanced neoplasia was $36 \%, 37 \%$, and $11 \%$, respectively. Pooled miss rate for adenomas was significantly higher for right-sided, non-pedunculated, and small $(<1 \mathrm{~cm})$ adenomas $(p=$ $0.031, p=0.000$, and $p=0.000$, respectively). The miss rate of polyps, adenomas, and advanced neoplasia per patient was 60\%, 49\%, and 7\%, respectively. Multivariate analysis revealed age and number of adenoma on initial colonoscopy were significantly related with risk for adenoma-missing ( $p=0.005$ and $p=0.023$, respectively). Conclusions: Among patients referred for polypectomy, adenoma is missed in one of two patients and advanced neoplasm is missed in one of 13. Patients with advanced age or multiple adenoma on initial colonoscopy have a higher possibility of missed adenoma. Total colon exploration should be performed carefully during therapeutic colonoscopy.

Keywords: Adenoma; Colonoscopy; Miss rate; Polyp

\section{INTRODUCTION}

Colonoscopic removal of adenomatous polyps decreases the incidence of colorectal cancer (CRC) $[1,2]$ and prevents CRC-related death [3]. Colonoscopy has been accepted as one of the most effective screening methods for colorectal neoplasia [4].

Nonetheless, CRCs are often diagnosed after a negative colonoscopy. Recent clinical studies suggest that etiology of these interval CRCs includes missed polyps, incompletely removed polyps, and de novo interval CRCs [5]. More than $50 \%$ of interval CRCs can be explained by 
missed lesions [6]. Therefore, emphasis has been placed on measures to increase the quality of colonoscopy. The indicators of high quality colonoscopy are classified as pre-procedural quality metrics (bowel preparation), procedural quality metrics (cecal intubation rate, withdrawal time, and adenoma detection rate $[A D R])$, and post-procedural quality metrics (surveillance interval) [7].

Although ADR is regarded as one of the most important quality metrics [8], a high ADR is not sufficient to guarantee a low adenoma miss rate (AMR), which may be more directly related to the development of interval CRC [9]. AMR can be measured by using back-to-back colonoscopy, which is almost impossible to perform in real-world practice.

Approximately 2.6 million cases of colonoscopy were performed in 2010 in Korea according to data from the Korean Health Insurance Review and Assessment Service [10]. Yet, little is known about colonoscopy quality of primary care clinics in Korea. According to a questionnaire-based study in Korea, only $57 \%$ and $87 \%$ of endoscopists in non-tertiary or non-academic hospital experienced EMR or polypectomy for colonic lesions [11]. When primary physicians detect polyps requiring snare polypectomy or endoscopic submucosal dissection during screening colonoscopy, it is a common practice to transfer the patient to secondary or tertiary hospitals for polypectomy. On the other hand, endoscopists in referral hospitals frequently detect missed polyps during therapeutic colonoscopy.

We performed this study to estimate colonoscopy quality of polypectomy-referring hospitals in Korea by evaluating polyp miss rate, AMR, and advanced neoplasm miss rate during colonoscopy for polypectomy. Risk factors associated with adenoma-missing were also explored.

\section{METHODS}

\section{Study population}

The study was approved by the Institutional Review Board at the Catholic University of Korea (KC18RESIoo14) and informed consent was waived. We retrospectively reviewed the medical records and electronic endoscopic images of initial colonoscopies from pol- ypectomy-referring hospitals and the corresponding therapeutic colonoscopies performed by a single expert endoscopist (L.B.I.) in Seoul St. Mary's Hospital between May 2014 and February 2016. Exclusion criteria were inflammatory bowel disease, unidentifiable procedure time, incomplete documentation, colorectal obstruction, and more than 6-month interval between initial and therapeutic colonoscopies.

\section{Review of medical records and electronic images}

Bowel preparation of initial colonoscopy in polypectomy-referring clinics was reassessed and scored using Aronchick bowel preparation scale [12] by reviewing all electronic images. Cecal intubation was confirmed by photodocumentation of cecal landmarks. Polyp number, size, morphology, location, and histology on initial colonoscopy were also evaluated by review of the electronic images and medical records by two of the authors (S.J.H. and L.B.I.). Unidentifiable variables were treated as missing values.

Bowel preparation scales and the number, size, morphology, locations, and histology of polyps of all the therapeutic colonoscopy in Seoul St. Mary's Hospital, The Catholic University of Korea were documented at the time of examination. A lesion located in the proximal colon (cecum to splenic flexure) was defined as the right colonic lesion. A lesion located distal to the splenic flexure was regarded as the left colonic lesion. Polyp morphology was classified according to the Paris classification [13]. Withdrawal time was estimated using documented time on electronic images. Time spent for biopsy and other therapeutic procedures was excluded. Advanced neoplasm was defined as adenoma with at least one of the following features: size $\geq 1 \mathrm{~cm}$, villous tissue $\geq 25 \%$, high grade dysplasia, and cancer.

\section{Definition}

Missed polyp/adenoma was defined as the polyp/adenoma not documented either by the electronic photos or endoscopy report during the initial colonoscopy, but which was detected during therapeutic colonoscopy. If a polyp was detected on initial colonoscopy and confirmed histologically as an adenoma later after therapeutic colonoscopy in Seoul St. Mary's Hospital, it was not regarded as a missed adenoma. Pooled miss rate for polyp/adenoma/advanced neoplasm was calculated as 
Table 1. Results of initial colonoscopy and therapeutic colonoscopy

\begin{tabular}{|c|c|c|c|}
\hline Variable & Initial colonoscopy $(\mathrm{n}=147)$ & Therapeutic colonoscopy $(\mathrm{n}=147)$ & $p$ value \\
\hline Cecal intubation & $147(100)$ & $147(100)$ & $>0.999$ \\
\hline Bowel preparation & & & $<0.001$ \\
\hline Excellent & $32(22)$ & $77(52)$ & \\
\hline Good & $37(25)$ & $42(29)$ & \\
\hline Fair & $75(51)$ & $26(18)$ & \\
\hline Poor & $3(2)$ & $2(1)$ & \\
\hline Mean withdrawal time, sec & $586 \pm 364$ & $736 \pm 452$ & 0.002 \\
\hline $\begin{array}{l}\text { Mean no. of detected polyps per pa- } \\
\text { tients }\end{array}$ & $2.4 \pm 1.7$ & & \\
\hline $\begin{array}{l}\text { Mean no. of detected adenomas per } \\
\text { patients }\end{array}$ & $1.7 \pm 1.4$ & & \\
\hline $\begin{array}{l}\text { Mean no. of additionally detected } \\
\text { polyps per patients }\end{array}$ & & $1.4 \pm 1.8$ & \\
\hline $\begin{array}{l}\text { Mean no. of additionally detected } \\
\text { adenomas per patients }\end{array}$ & & $1.0 \pm 1.5$ & \\
\hline
\end{tabular}

Values are presented as number (\%) or mean \pm SD.

Table 2. Pooled miss rate for polyp, adenoma, and advanced adenoma

\begin{tabular}{lcccc}
\hline Variable & $\begin{array}{c}\text { Detected on initial } \\
\text { colonoscopy }\end{array}$ & $\begin{array}{c}\text { Additionally detected on } \\
\text { therapeutic colonoscopy }\end{array}$ & Total & Miss rate, \% \\
\hline No. of polyp & 351 & 198 & 549 & 36 \\
No. of adenoma & 249 & 147 & 396 & 37 \\
No. of advanced neoplasia & 92 & 11 & 103 & 11 \\
\hline
\end{tabular}

the number of missed polyps/adenomas/advanced neoplasia divided by the total number of polyps/adenomas/ advanced neoplasia of all patients.

Miss rate of polyp/adenoma/advanced neoplasm per patient was calculated as the number of patients with missed polyps/adenomas/advanced neoplasia divided by the total number of patients.

\section{Statistical analyses}

Statistical analyses were performed using SPSS for Windows software version 18.0 (SPSS Inc., Chicago, IL, USA). A $p<0.05$ was considered significant. Demographic data including age, gender, size, morphology, locations, pathology, and number of polyps and adenomas were included to identify the variables associated with missed adenomas. Continuous variables were analyzed using $t$ test and categorical variables were analyzed using chisquare test or Fisher's exact test. Statistical adjustment using multivariate linear regression was applied to identify the variables relevant to adenoma-missing.

\section{RESULTS}

\section{Baseline characteristics}

Among 197 eligible patients, 50 were excluded (inflammatory bowel disease, $\mathrm{n}=1$; unidentifiable procedure time, $\mathrm{n}=23$; incomplete documentation, $\mathrm{n}=11$; colorectal obstruction, $\mathrm{n}=4$; and more than 6-month interval between initial colonoscopy and therapeutic colonoscopy, $\mathrm{n}=11$ ). A total of 147 patients were finally included.

The mean \pm standard deviation age was $56.6 \pm 12.1$ years and male was 110 (75\%). Cecal intubation was successful in all cases of initial colonoscopy and therapeutic colonoscopy. Mean withdrawal time of therapeutic colonoscopy was significantly longer than that of initial 
Table 3. Pooled miss rate for polyp by polyp characteristics

\begin{tabular}{|c|c|c|c|c|}
\hline Characteristic & $\begin{array}{l}\text { Detected on initial } \\
\text { colonoscopy }(\mathrm{n}=\mathbf{2 2 1})\end{array}$ & $\begin{array}{l}\text { Additionally detected on } \\
\text { therapeutic colonoscopy }(n=195)\end{array}$ & Miss rate, $\%$ & $p$ value \\
\hline \multicolumn{5}{|l|}{ Location } \\
\hline Right colon & 128 & 128 & 50 & 0.022 \\
\hline Left colon & 93 & 67 & 42 & \\
\hline \multicolumn{5}{|l|}{ Morphology } \\
\hline Pedunculated (Ip) & 20 & 2 & 9 & $<0.001$ \\
\hline Non-pedunculated (Is and IIa) & 201 & 193 & 49 & \\
\hline \multicolumn{5}{|l|}{ Size, $\mathrm{mm}$} \\
\hline$\leq 5$ & 39 & 96 & 71 & $<0.001$ \\
\hline $6-9$ & 78 & 84 & 52 & \\
\hline$\geq 10$ & 104 & 15 & 13 & \\
\hline
\end{tabular}

Table 4. Pooled miss rate for adenoma by adenoma characteristics

\begin{tabular}{|c|c|c|c|c|}
\hline Characteristic & $\begin{array}{l}\text { Detected on initial } \\
\text { colonoscopy }(n=179)\end{array}$ & $\begin{array}{l}\text { Additionally detected on } \\
\text { therapeutic colonoscopy }(\mathrm{n}=150)\end{array}$ & Miss rate, $\%$ & $p$ value \\
\hline \multicolumn{5}{|l|}{ Location } \\
\hline Right colon & 101 & 102 & 50 & 0.031 \\
\hline Left colon & 78 & 48 & 38 & \\
\hline \multicolumn{5}{|l|}{ Morphology } \\
\hline Pedunculated (Ip) & 19 & 1 & 5 & $<0.001$ \\
\hline Non-pedunculated (Is and IIa) & 160 & 149 & 48 & \\
\hline \multicolumn{5}{|l|}{ Size, $\mathrm{mm}$} \\
\hline$\leq 5$ & 28 & 77 & 73 & $<0.001$ \\
\hline $6-9$ & 60 & 62 & 51 & \\
\hline$\geq 10$ & 91 & 11 & 11 & \\
\hline \multicolumn{5}{|l|}{ Pathology } \\
\hline Tubular adenoma, low grade & 135 & 143 & 51 & $<0.001$ \\
\hline Tubular adenoma, high grade & 8 & 1 & 11 & \\
\hline Tubulovillous or villous adenoma & 14 & o & o & \\
\hline Sessile serrated adenoma/polyp & 12 & 6 & 33 & \\
\hline Intraepithelial or mucosal cancer & 10 & o & 0 & \\
\hline \multicolumn{5}{|l|}{ Advanced lesion } \\
\hline Non-advanced adenoma & 85 & 139 & 62 & $<0.001$ \\
\hline Advanced neoplasia & 94 & 11 & 11 & \\
\hline
\end{tabular}

colonoscopy (736 seconds vs. 586 seconds, $p=0.002$ ). The proportion of patients with excellent or good preparation was higher in therapeutic colonoscopy than in initial colonoscopy ( $81 \%$ vs. $47 \%, p<0.001)$.

A total of 549 polyps (396 adenomas including 103 advanced neoplasia) were detected on the 147 pairs of colonoscopy examinations. The mean number of total polyps and adenomas per patient was 3.8 and 2.7, respectively. Mean number of missed polyps and adenomas per patient was 1.4 and 1.0, respectively (Tables 1 and 2). 


\section{Pooled miss rate for polyps, adenomas, and advanced neoplasia}

Among a total of 549 polyps, 198 were not detected on initial colonoscopy, representing a pooled miss rate for polyps of $36 \%$. The pooled miss rate for adenomas and advanced neoplasia was $37 \%$ and $11 \%$, respectively (Table 2).

Location, morphology, and size were analyzed for 416 polyps with available medical records. Pooled miss rate for polyps was significantly higher in the right colon than in the left colon ( $50 \%$ vs. $42 \%, p=0.022$ ), and was also higher in non-pedunculated polyps (Is and IIa) than in pedunculated polyps (Ip) (49\% vs. $9 \%, p<0.001$ ). Pooled miss rate for polyps was significantly different according to the size: $71 \%$ in polyps $\leq 5 \mathrm{~mm}, 52 \%$ in polyps of 6 to $9 \mathrm{~mm}$, and $13 \%$ in polyps $\geq 10 \mathrm{~mm}(p<0.001)$ (Table 3).

Among the 396 adenomas, location, morphology, and size could be analyzed in 329 adenomas. Pooled miss rate for adenomas was higher in the right colon than in the left colon ( $50 \%$ vs. $38 \%, p=0.031$ ), and in non-pedunculated adenomas than in pedunculated adenomas ( $48 \%$ vs. $5 \%, p<0.001)$. Pooled miss rate for adenomas was significantly different according to the size of adenoma: $73 \%$ in adenomas $\leq 5 \mathrm{~mm}, 51 \%$ in adenomas of 6 to 9 $\mathrm{mm}$, and $11 \%$ in adenomas $\geq 10 \mathrm{~mm}(p<0.001)$. Pooled miss rate for non-advanced neoplasia was significantly higher than pooled miss rate for advanced neoplasia (62\% vs. $11 \%, p<0.001$ ) (Table 4 ).

All the missed advanced neoplasia were $\geq 10 \mathrm{~mm}$. Ten of 11 were flat and located in the right colon. Histopathology was low grade dysplasia $(\mathrm{n}=8)$, high grade dysplasia $(n=1)$, and sessile serrated adenoma/polyp $(n=2)$.

\section{Miss rate of polyps, adenomas, and advanced neoplasia per patient}

Among a total of 147 patients, those with missed polyps, adenomas, and advanced neoplasia was 88,72 , and 11 , corresponding to a respective miss rate of $60 \%, 49 \%$, and $7 \%$.

\section{Risk factors for adenoma-missing}

Mean age of patients with missed adenoma was significantly higher than patients without missed adenoma (53.1 \pm 11.9 vs. $60.4 \pm 11.3, p=0.000)$. There was no significant difference in sex, mean withdrawal time, and preparation scale of initial colonoscopy between the two groups. The mean number of adenomas detected during the initial colonoscopy was higher in patients

Table 5. Differences in clinical characteristics of patients without missed adenoma and patients with missed adenoma

\begin{tabular}{|c|c|c|c|}
\hline Characteristic & $\begin{array}{l}\text { Patients without missed adenoma } \\
\qquad(\mathrm{n}=77)\end{array}$ & $\begin{array}{l}\text { Patients with missed adenoma } \\
\qquad(\mathrm{n}=70)\end{array}$ & $p$ value \\
\hline Age, yr & $53.1 \pm 11.9$ & $60.4 \pm 11.3$ & $<0.001$ \\
\hline Sex & & & 0.474 \\
\hline Male & 60 & 50 & \\
\hline Female & 17 & 20 & \\
\hline $\begin{array}{l}\text { Mean withdrawal time of initial } \\
\text { colonoscopy, sec }\end{array}$ & $619 \pm 386$ & $549 \pm 337$ & 0.249 \\
\hline $\begin{array}{l}\text { Bowel preparation for initial } \\
\text { colonoscopy }\end{array}$ & & & 0.609 \\
\hline Excellent & $14(18)$ & $18(26)$ & \\
\hline Good & $20(26)$ & $17(24)$ & \\
\hline Fair & $42(55)$ & $33(47)$ & \\
\hline Poor & $1(1)$ & $2(3)$ & \\
\hline $\begin{array}{l}\text { Mean no. of polyp detected during } \\
\text { initial colonoscopy }\end{array}$ & $2.2 \pm 1.6$ & $2.7 \pm 1.8$ & 0.096 \\
\hline $\begin{array}{l}\text { Mean no. of adenoma detected } \\
\text { during therapeutic colonoscopy }\end{array}$ & $1.4 \pm 1.2$ & $2.0 \pm 1.5$ & 0.009 \\
\hline
\end{tabular}

Values are presented as mean $\pm \mathrm{SD}$ or number (\%). 
Table 6. Multivariate analysis for risk factors of adenoma missing

\begin{tabular}{lccc}
\hline Variable & $\mathrm{b}(\mathrm{SE})$ & $\beta$ & $p$ value \\
\hline Age & $0.031(0.011)$ & 0.245 & 0.005 \\
No. of polyps detected during initial colonoscopy & $-0.087(0.107)$ & -0.096 & 0.419 \\
No. of adenomas detected during initial colonoscopy & $0.314(0.136)$ & 0.292 & 0.023 \\
Withdrawal time of initial colonoscopy & $0.000(0.000)$ & -0.033 & 0.675 \\
Bowel preparation of initial colonoscopy & $-0.185(0.145)$ & -0.101 & 0.204 \\
\hline
\end{tabular}

SE, standard error.

with missed adenoma than in patients without missed adenoma ( $2.0 \pm 1.5$ vs. $1.4 \pm 1.2, p=0.009)$ (Table 5).

Multivariate linear regression analysis also revealed that age and number of adenomas detected during initial colonoscopy were associated with risk of adenoma-missing (Table 6).

\section{DISCUSSION}

ADR is inversely associated with the incidence of interval CRC [14] and CRC mortality [15]. Although ADR has been accepted as a priority quality metric for colonoscopy [8], it is not a perfect metric. It cannot differentiate an endoscopist who consistently finds multiple adenomas from an endoscopist who only finds one adenoma ("one and done" phenomenon). To better measure the quality of colonoscopy, adenomas detected per colonoscopy, adenomas per positive participant, and the number of additional adenomas found after the first adenoma per colonoscopy (ADR-Plus) were adopted [16].

To best of our knowledge, there has not been any real-world study of colonoscopy quality in Korea using quality metrics. If AMR could be measured in daily practice, it would be a more appropriate quality metric for colonoscopy, since the majority of interval CRCs are associated with missed adenomas. Presently, we measured AMRs of polypectomy-referring hospitals by comparing their colonoscopic findings and our findings during colonoscopy for polypectomy. Many primary care physicians doing colonoscopy do not perform snare polypectomy in Korea because of the limited procedure time for an individual patient, difficulties in post-polypectomy care including management of bleeding or perforation, concerns about legal issues, and other reasons. Certainly, this is an irrational use of medical resources, since the prevalence of colorectal neoplasms among asymptomatic patients who are screened was reported as 33\% in Korea [17]. This indicates that a number of patients requiring polypectomy should have a repeat consecutive colonoscopy within a short period of time.

AMRs has been reported as $17 \%$ to $25 \%[9,18,19]$ and our pooled miss rate for adenomas, which is compatible with AMR of other studies, was measured 37\%. Our miss rate could be augmented since all the study subjects had polyps and meticulous endoscopic examination or documentation in primary care clinics might be omitted after detection of a polyp requiring referral. We believe that better preparation and longer withdrawal time of our therapeutic colonoscopies compared to the initial colonoscopies may also have contributed to the high AMR of the present study.

Our results show that smaller adenomas are more frequently missed, which is consistent with previous studies [18-21]. Diminutive or small adenomas are frequently undetected when they are located behind a fold or submerged in the luminal fluid. Although study results for adenoma location and miss rate are controversial, it was reported that adenomas in the right colon were more frequently missed [19,20,22,23]. Adenoma detection could be interfered by higher mucosal folds of the right colon.

Even though the AMR of this study might be augmented, the miss rate of adenoma per patient $48 \%$ was still very high. That means that almost half the patients referred for polypectomy harbored missed adenomas. Moreover, the $7 \%$ miss rate of advanced neoplasia per patient indicates that approximately one of 13 subjects harbored a missed advanced neoplasm or more. This clearly suggests that the quality of colonoscopy delivered by primary care clinics needs to be improved in Korea.

Various factors influencing AMR per patient were 
suggested in previous studies as follows: number of adenoma detected during initial colonoscopy $[18,19,23]$, characteristics of individual endoscopists $[9,24]$, and age of patient $[24,25]$. Our multivariate analysis showed only age of patient and number of adenoma on initial colonoscopy were significantly related with presence of missed adenoma. It is unclear why age of patient is related with AMR. The positive relationship between the number of adenoma during initial colonoscopy and AMR can be explained by a reduced attention after having already detected polyps and time pressure on endoscopists due to a remained endoscopy list for that day [23].

Our multivariate analysis revealed that withdrawal time and bowel preparation of initial colonoscopy were not significantly related with presence of missed adenoma. Increased number of polyps including adenomas itself could be related with prolonged withdrawal time. Even though time spent for biopsy and polypectomy was excluded, extra time for photodocumentation and close observation should be spent. Prolonged withdrawal time of initial colonoscopy might be related with the time for already-detected polyps rather than undetected polyps. Regarding preparation scale of initial colonoscopy, advanced age is an independent risk factor for inadequate bowel preparation [26]. Thus the effect of bowel preparation scale of initial colonoscopy could be reduced in multivariate analysis.

This study has several limitations. First, it is a retrospective study based on review of medical records. Aronchick bowel preparation scale should be scored before any attempt of washing and suctioning. Thus, another bowel preparation scale such as Boston bowel preparation score [27] might be more suitable for assessment of bowel preparation in polypectomy-referring hospitals. However, retrospective assessment of each colonic segment in Boston score was not easy. Moreover, at the time of the study, all the bowel preparation scale in our institution was scored using Aronchick scale. Thus we decided to apply Aronchick scare to compare bowel preparation scale between polypectomy-referring hospitals and our institution. Estimation of accurate withdrawal time was also limited since it was based on retrospective review of the electronic images. Second, we cannot evaluate the AMR according to characteristics of individual endoscopist or polypectomy-referring hospital because of limited information. Finally, the AMR could be over- estimated by the "one-and-done phenomenon." On the contrary, exclusion of cases with unidentifiable procedure time or incomplete documentation, which might be associated with poor quality colonoscopy, could lead to underestimation of the AMR.

In conclusion, the AMR of polypectomy-referring hospitals is high in Korea. Meticulous total colon exploration should be performed during therapeutic colonoscopy and nation-wide monitoring of colonoscopy quality is definitely necessary.

\section{KEY MESSAGE}

1. Among patients referred for polypectomy, adenoma miss rate and advanced-adenoma miss rate per patients are $48 \%$ and $7 \%$, respectively.

2. Age of patient and number of adenoma on initial endoscopy are independent risk factors of adenoma-missing.

\section{Conflict of interest}

No potential conflict of interest relevant to this article was reported.

\section{REFERENCES}

1. Winawer SJ, Zauber AG, Ho MN, et al. Prevention of colorectal cancer by colonoscopic polypectomy. The National Polyp Study Workgroup. N Engl J Med 1993;329:19771981.

2. Citarda F, Tomaselli G, Capocaccia R, Barcherini S, Crespi M; Italian Multicentre Study Group. Efficacy in standard clinical practice of colonoscopic polypectomy in reducing colorectal cancer incidence. Gut 2001;48:812815 .

3. Zauber AG, Winawer SJ, O'Brien MJ, et al. Colonoscopic polypectomy and long-term prevention of colorectal-cancer deaths. N Engl J Med 2012;366:687-696.

4. Rex DK, Johnson DA, Lieberman DA, Burt RW, Sonnenberg A. Colorectal cancer prevention 2000: screening recommendations of the American College of Gastroenterology. American College of Gastroenterology. Am J Gastroenterol 2000;95:868-877.

5. Cisyk AL, Singh H, McManus KJ. Establishing a biolog- 
ical profile for interval colorectal cancers. Dig Dis Sci 2014;59:2390-2402.

6. le Clercq CM, Bouwens MW, Rondagh EJ, et al. Postcolonoscopy colorectal cancers are preventable: a population-based study. Gut 2014;63:957-963.

7. Hancock KS, Mascarenhas R, Lieberman D. What can we do to optimize colonoscopy and how effective can we be? Curr Gastroenterol Rep 2016;18:27.

8. Rex DK, Schoenfeld PS, Cohen J, et al. Quality indicators for colonoscopy. Am J Gastroenterol 2015;110:72-90.

9. Aniwan S, Orkoonsawat P, Viriyautsahakul V, et al. The secondary quality indicator to improve prediction of adenoma miss rate apart from adenoma detection rate. Am J Gastroenterol 2016;111:723-729.

10. Heath Unsurance Review and Assessment Service. Healthcare Bigdata Hub [Internet]. Wonju (KR): Heath Unsurance Review and Assessment Service, c2017 [cited 2019 Sep 4]. Availble from: https://www.hira.or.kr.

11. Jeon SW, Jung MK, Kim SK, et al. Is endoscopic resection currently available in non-tertiary or non-academic hostitals? Korean J Gastrointest Endosc 2010 41:338-343.

12. Aronchick CA, Lipshutz WH, Wright SH, Dufrayne F, Bergman G. A novel tableted purgative for colonoscopic preparation: efficacy and safety comparisons with Colyte and Fleet Phospho-Soda. Gastrointest Endosc 2000;52:346-352.

13. Participants in the Paris Workshop. The Paris endoscopic classification of superficial neoplastic lesions: esophagus, stomach, and colon: November 30 to December 1, 2002. Gastrointest Endosc 2003;58:S3-S43.

14. Kaminski MF, Regula J, Kraszewska E, et al. Quality indicators for colonoscopy and the risk of interval cancer. N Engl J Med 2010;362:1795-1803.

15. Corley DA, Levin TR, Doubeni CA. Adenoma detection rate and risk of colorectal cancer and death. N Engl J Med 2014;370:2541.

16. Dominitz JA, Spiegel B. Editorial: on the quality of quality metrics: rethinking what defines a good colonoscopy. Am J Gastroenterol 2016;111:730-732.
17. Park HW, Byeon JS, Yang SK, et al. Colorectal neoplasm in asymptomatic average-risk Koreans: the KASID prospective multicenter colonoscopy survey. Gut Liver 2009;3:3540.

18. Ahn SB, Han DS, Bae JH, Byun TJ, Kim JP, Eun CS. The miss rate for colorectal adenoma determined by quality-adjusted, back-to-back colonoscopies. Gut Liver 2012;6:64-70.

19. Rex DK, Cutler CS, Lemmel GT, et al. Colonoscopic miss rates of adenomas determined by back-to-back colonoscopies. Gastroenterology 1997;112:24-28.

20. Heresbach D, Barrioz T, Lapalus MG, et al. Miss rate for colorectal neoplastic polyps: a prospective multicenter study of back-to-back video colonoscopies. Endoscopy 2008;40:284-290.

21. van Rijn JC, Reitsma JB, Stoker J, Bossuyt PM, van Deventer SJ, Dekker E. Polyp miss rate determined by tandem colonoscopy: a systematic review. Am J Gastroenterol 2006;101:343-350.

22. Choi HN, Kim HH, Oh JS, et al. Factors influencing the miss rate of polyps in a tandem colonoscopy study. Korean J Gastroenterol 2014;64:24-30.

23. Leufkens AM, van Oijen MG, Vleggaar FP, Siersema PD. Factors influencing the miss rate of polyps in a back-toback colonoscopy study. Endoscopy 2012;44:470-475.

24. Munroe CA, Lee P, Copland A, et al. A tandem colonoscopy study of adenoma miss rates during endoscopic training: a venture into uncharted territory. Gastrointest Endosc 2012;75:561-567.

25. Kim JH, Kim YS, Cheon JH, et al. Influence of the insertion time and number of polyps on miss rate in colonoscopy. Scand J Gastroenterol 2011;46:634-639.

26. Sim JS, Koo JS. Predictors of inadequate bowel preparation and salvage options on colonoscopy. Clin Endosc 2016;49:346-349.

27. Lai EJ, Calderwood AH, Doros G, Fix OK, Jacobson BC. The Boston bowel preparation scale: a valid and reliable instrument for colonoscopy-oriented research. Gastrointest Endosc 2009;69:620-625. 